\title{
Real-world effectiveness of osteoporosis treatment in the oldest old
}

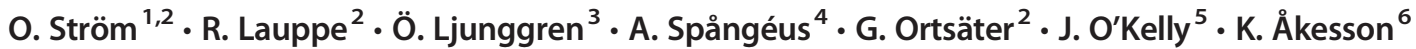

Received: 28 June 2019 / Accepted: 5 March 2020 / Published online: 30 March 2020

(C) The Author(s) 2020

\begin{abstract}
Summary We studied effectiveness of osteoporosis treatment in women older than 80 years, who often are not included in clinical trials. Treatments were as effective on bone density and fractures as in younger women.

Introduction To study real-world effectiveness of osteoporosis treatment on BMD and fractures in the oldest old women $(\geq$ 80 years) compared with women (60-79 years) in the clinical setting using Swedish health register data.

Methods National registers and data from DXA machines were used to study effectiveness of all available osteoporosis treatments in women 60-79 and $\geq 80$ years using three approaches: (1) Total Hip BMD change up to 8 years after treatment start; (2) fracture incidence where patients served as their own controls, comparing the first 3 months after treatment start with the subsequent 12 months; and (3) comparison of fracture incidence post-fracture in women $\geq 80$ years treated with osteoporosis treatment or calcium/vitamin D.

Results Analysis 1: Total Hip BMD increased by up to $6.7 \%$ and $7.7 \%$ in women $60-79$ and $\geq 80$ years old, respectively. The mean increase in BMD was 1.1\%-units per year in both age groups. Analysis 2: Relative to the 3-month baseline, fracture incidence decreased during the subsequent 12 months of treatment. Incidence rate ratios were estimated at $0.65,0.74,0.29$, and 0.81 for any, hip, vertebral, and non-hip-non-vertebral fracture, respectively. Analysis 3: A 24-month incidence of any fracture in women $\geq 80$ years given post-fracture osteoporosis treatment was lower $(H R=0.78)$ than in women given calcium/vitamin $D$, but treatment allocation was not random, with lower mortality $(\mathrm{HR}=0.51)$ in patients receiving OP treatment.

Conclusions Osteoporosis medication in women $>80$ years in clinical practice likely works, and the magnitude of effect is similar to what was estimated in younger women. The choice between osteoporosis treatment and calcium/vitamin D after fracture in women $\geq 80$ years is not random but appears associated with the patient's health status and presence of vertebral fractures, rather than the known risk profile of sustaining a fracture at a high age.
\end{abstract}

Keywords Bisphosphonates $\cdot$ Bone mineral density $\cdot$ Elderly $\cdot$ Retrospective $\cdot$ Register $\cdot$ Women

Electronic supplementary material The online version of this article (https://doi.org/10.1007/s00198-020-05380-6) contains supplementary material, which is available to authorized users.

O. Ström

oskar.strom@quantifyresearch.com

Karolinska Institutet, Stockholm, Sweden

2 Quantify Research, Stockholm, Sweden

3 Uppsala University, Uppsala University Hospital, Uppsala, Sweden

4 Linköping University, Linköping University Hospital, Linköping, Sweden

5 Amgen Ltd, Uxbridge, UK

6 Lund University, Skåne University Hospital, Malmö, Sweden

\section{Introduction}

The fracture incidence rate among women aged 80 and older $(80+)$, sometimes referred to as the "oldest old", is considerably higher than among younger women [1-3]. Fractures in older individuals also entail more serious consequences for the patient and higher costs for society compared with fractures in younger individuals $[4,5]$. With a growing elderly population, the incidence of fractures will increase over the coming decades, and the number of hip fractures, generally associated with high impact on morbidity and mortality, is estimated to double in the first half of this century [6-8]. The efficacy of the available pharmacological agents for the treatment of osteoporosis in increasing bone strength and reducing osteoporotic fracture risk is well-established, although this evidence is generally better for the prevention of vertebral fractures than that for non-vertebral and hip fractures. The bulk of the 
evidence of efficacy rests on RCTs in postmenopausal women between the ages of 50 and 80 years and the evidence of antiosteoporotic efficacy in the oldest old have come primarily from subgroup analyses. Nonetheless, evidence of efficacy in the oldest old is supported by randomized studies, reviewed in an ESCEO consensus article by Rizzoli and colleagues [9]. However, patients treated in clinical practice are more heterogeneous, less adherent to treatment, may have comorbidities or other characteristics excluding them from RCTs, and may be treated for both shorter and longer periods than typically recommended. It is therefore of importance to study if the effectiveness reported in RCTs can be generalized to clinical practice. Notable studies of effectiveness in older patients have been published by Abelson et al. [10] and Axelsson et al. [11] who both reported risk reductions with alendronate, but with varying designs and definitions, as is often the case in real-world effectiveness studies. Osteoporosis treatments are frequently found to be under-prescribed in many countries [12], also in women who have sustained a fracture. Eleven percent of treatment-naïve Swedish women 70-79 years old received treatment within 12 months after a fracture, whereas the corresponding figure for women $>80$ years is $6 \%$ [13]. Moreover, only $4 \%$ of women $\geq 80$ years had undergone a DXA within 6 months after fracture [data on file] which may indicate that thorough risk assessment is unusual and that treatment decisions partly are based on other factors than those traditionally governing fracture risk. The reasons for the poor treatment provision are not clear but could relate to that osteoporosis sometimes is regarded to be a natural part of ageing, that other concomitant diseases should be prioritized, and that expected remaining life expectancy is too short to reap the benefits of fracture prevention.

The objective was to study the real-world effectiveness of osteoporosis treatment in the oldest old women ( $\geq 80$ years) compared with younger women (60-79 years) in the clinical setting using both BMD and fracture as outcomes.

\section{Methods}

\section{Source data, participants, and study design}

The study used the Nordic Osteoporosis Research Dataset (NORD), which contains $>1$ million patients with fracture, $>$ 400,000 with osteoporosis treatment, and $>55,000$ with BMD measurements. All data were linked via a unique patient ID and spans from 2000 to 2016. Data on diagnoses, pharmaceuticals, and mortality were extracted from the National Patient Register, the Swedish Prescribed Drug Register, and the Cause of Death Register, respectively. A DXA population was selected from three databases containing BMD data (Malmö, Uppsala and Linköping) and included women with at least one BMD measurement between the dates 1 July 2007 and 31 December 2015 while being $\geq 50$ years old. The research was approved by the Stockholm ethics review board and the data holders.

This was a retrospective, observational cohort study using three distinct study cohorts drawn from NORD to study the effectiveness of osteoporosis therapy in the oldest old $(\geq 80)$ compared with younger populations (60-79 years) and, in one of the analyses, with subjects receiving calcium/vitamin D. The three different approaches described below were chosen to complement each other to account for the use of nonrandomized retrospective data, which are limited by bias to some extent. Women with a diagnosis of Paget's disease at any time point during the study period or with a primary diagnosis of secondary malignant neoplasm of bone and bone marrow at any time point during the individual look-back period or follow-up were excluded. Identification of fractures was based on primary ICD-10 codes in inpatient and outpatient hospital care, including ER visits and outpatient referrals from primary care. Fractures coded for the same body site as a previous fracture were disregarded and counted as a follow-up visit if coded in the outpatient setting. Inpatient fractures at the same body site were counted as a rehospitalization related to the previous fracture, unless $\geq 6$ months had passed from the previous fracture. When adjusted, statistical models for fracture outcomes were controlled for age, Charlson comorbidity index, glucocorticoid use, pre-packaged drug dispensing, index fracture type, exposure to drugs increasing the risk of falls, and use of proton pump inhibitors. Models with TH BMD as outcome were adjusted for baseline T-score $\leq-2.5 \mathrm{SD}$, glucocorticoid use, and use of proton pump inhibitors.

\section{Analysis 1: T-score and percent change in total hip BMD in treated women $60-79$ and 80 years or older}

The analysis of T-score and percent change in BMD over time in women who started osteoporosis treatment was performed on total hip BMD because this measurement was found superior to lumbar spine for predicting fracture risk in a study of risk factors performed on the same dataset [14]. Women who had started an osteoporosis treatment ${ }^{1}$ and undergone at least two total hip BMD measurements were followed for up to 8 years from the dispensing of the first prescription (index). The first BMD measurement should have taken place no longer than 12 months before or after treatment start. To capture the real-world treatment effect on BMD, patients who discontinued treatment were not removed from observation at the time of discontinuation, and switching to other treatments during follow-up was allowed. Changes in BMD over time was also analysed in a subset of patients that were still persistent to treatment at the time of the DXA scan. Patients were defined as non-persistent if they did not fill a new prescription within 60 days from when their previous dispensing

\footnotetext{
${ }^{1}$ Alendronate, denosumab, raloxifene, risedronate, teriparatide, or zoledronate
} 
should have been consumed. Consumption of medication surplus was allowed. Follow-up was dived into 12-month windows and each patient had a baseline BMD at $t_{0}$ and between one and six repeat measurements. Total hip BMD was measured on Lunar DPX and Hologic Discovery. Data was standardized and converted using the International DXA Standardization Committee (IDSC) [15].

Percent change in total hip BMD was used as outcome, and each follow-up year containing a BMD measurement was used in the estimation. Patient characteristics were measured during 24 months prior to index treatment. An unadjusted population averaged generalized linear panel data model was used to estimate the change per year while accounting for contribution of data by different patients at different time points and correlation of within-subject measurements.

\section{Analysis 2: effectiveness in women $60-79$ vs. $80+$ using patients as their own control}

Observational studies have examined the effectiveness of osteoporosis treatments for reducing clinical fractures. The designs of these observational studies include comparisons between patients with or without bisphosphonate use [16, 17] and compliant or not compliant with bisphosphonate use [18-20]. A key limitation in interpreting any of these comparisons is uncertainty whether known or unknown differences in baseline fracture risk between patient populations account for some of the estimated effect. Abelson and colleagues [10] proposed a method where the first 3 months after treatment start (index time point) serves as a proxy for the untreated baseline risk, thereby allowing patients to serve as their own control. Using this method, we estimated change in fracture incidence as incidence rate ratios (IRRs) in the oldest old compared with younger women using hip, vertebral, and nonhip-non-vertebral (NHNV) as fracture outcomes. Included patients had started a treatment during July 2007-August 2013 after a treatment free period of at least 24 months and with at least 4 months of follow-up. Patients were required to be persistent to treatment during their entire included follow-up, but switching between osteoporosis treatments during follow-up was allowed. Follow-up was limited to 15 months $(3+12)$ to avoid capturing time-dependent changes not caused by the treatment. Patient characteristics were measured during 24 months before index. An unadjusted multiple failure Poisson survival model was chosen for fracture outcomes to avoid that women who fracture during the first 3 months were removed from the later period (4-15 months after treatment).

\section{Analysis 3: effectiveness of osteoporosis treatment vs. calcium/vitamin D therapy after clinical fracture in women 80 years or older}

Resting on the hypothesis that in women 80 years or older the group-level treatment allocation after fracture is mainly random, or dependent on other factors not directly associated with fracture risk, a comparison of fracture risk and mortality was made between treatment-naive women who had received at least one prescription of osteoporosis treatment after fracture (intention-to-treat, ITT group) and treatment-naïve women who instead had received therapy with calcium/vitamin D (>73,200 IU during the first 6 months of treatment). Treatment with osteoporosis medication or calcium/vitamin D had to start between July 2007 and August 2013 and within 6 months after the fracture. Follow-up was limited to 24 months after treatment initiation (the index time point). Switching to other treatments was allowed after 6 months of follow-up in the ITT group and calcium/vitamin D group. Risk of any fracture was compared between treatment cohorts using an adjusted standard Cox model and an adjusted FineGray competing risk model, accounting for death as a competing event. The sample did not allow analysis of separate outcome fracture types.

\section{Results}

\section{Patient characteristics}

Patient characteristics (Table 1) for the cohorts and subgroups studied in analyses 1 and 2 indicated that there were differences in comorbidities and concomitant medication between the age groups, as expected. Further, prior hip and vertebral fractures were more frequent, and BMD was lower in older women. Patient characteristics for the women in analysis 3 show that prior vertebral fracture was clearly relatively more frequent than other fracture types among women treated with osteoporosis medication than those who received calcium/ vitamin D. There was also a pattern that women who had received calcium/vitamin D were slightly older, had more comorbidities, and were more than twice as likely to receive prepackaged medication, which is indicative of special living conditions (e.g. nursing homes or extra care housing), home help, or other forms for assistance needs (Tables 2 and 3).

\section{Analysis 1: TH BMD over time in patients starting treatment}

Repeated DXA scans of total hip (TH) BMD were available for 2161 women who had started an osteoporosis treatment. The majority (74\%) had only two measurements, $21 \%$ had three, and 5\% underwent $\geq 4$ DXA scans, and the most frequent time point for a repeat measurement was during the third year after the baseline DXA. The linear percent change in $\mathrm{TH}$ BMD was estimated at $+1.13 \%$ units [1.03-1.22] per year, and there was no statistically significant difference between age groups $(p=0.309)$. The results did not change when running a fully adjusted model $\left(+1.05 \%\right.$ units $\left[\mathrm{CI}_{95}\right.$ 0.93-1.17] per year). Percent change in TH BMD was also associated 
Table 1 Patient characteristics (measured during 24 months look-back from index, unless otherwise specified)

\begin{tabular}{|c|c|c|c|c|c|c|}
\hline & \multicolumn{2}{|c|}{$\begin{array}{l}\text { Analysis 1: Total hip BMD } \\
\text { over time in patients starting } \\
\text { treatment }\end{array}$} & \multicolumn{2}{|c|}{$\begin{array}{l}\text { Analysis } 2 \text { : Fracture } \\
\text { incidence in patients starting } \\
\text { treatment used as own } \\
\text { control ( } 0-3 \text { months vs. } 4- \\
15 \text { months) }\end{array}$} & \multicolumn{2}{|c|}{$\begin{array}{l}\text { Analysis 3: Fracture incidence } \\
\text { after starting osteoporosis } \\
\text { treatment vs. calcium/vitamin } \\
\text { D after fracture in women } 80+\end{array}$} \\
\hline & 60-79 years & $80+$ & $60-79$ years & $80+$ & $\begin{array}{l}\text { Osteoporosis } \\
\text { treatment }\end{array}$ & Calcium/vitamin D \\
\hline$n$ & 1907 & 254 & 81,039 & 35,542 & 5272 & 20,533 \\
\hline Follow-up in years (mean, ( min-max)) & $3.5(0.5-8.4)$ & $2.9(0.6-6.9)$ & $0.8(0.3-1.3)$ & $0.8(0.3-1.3)$ & $1.6(0.0-2.0)$ & $1.5(0.0-2.0)$ \\
\hline Age at index (mean) & 69.0 & 83.0 & 70.3 & 84.4 & 84.4 & 86.7 \\
\hline Prior fracture, any $(\%)$ & 25.1 & 29.9 & 25.0 & 32.8 & 100.0 & 100.0 \\
\hline Hip (\%) & 3.9 & 11.0 & 4.7 & 11.1 & 31.3 & 43.2 \\
\hline Vertebral (\%) & 4.1 & 5.5 & 3.9 & 8.9 & 32.4 & 14.0 \\
\hline Non-hip, non-vertebral (\%) & 17.9 & 15.4 & 17.5 & 16.1 & 41.5 & 45.3 \\
\hline Previous OP treatment $(\%)$ & 0.0 & 0.0 & 0.0 & 0.0 & 0.0 & 0.0 \\
\hline Diagnose related to secondary osteoporosis $(\%)$ & 13.3 & 15.4 & 15.0 & 15.2 & 18.0 & 19.5 \\
\hline Systemic glucocorticoid use (\%) & 18.4 & 14.6 & 33.1 & 31.5 & 17.0 & 15.8 \\
\hline Charlson-Quan comorbidity index $=0(\%)$ & 68.3 & 53.9 & 65.2 & 58.2 & 50.4 & 42.4 \\
\hline Charlson-Quan comorbidity index $=1-2(\%)$ & 25.9 & 33.1 & 27.3 & 32.9 & 39.0 & 44.3 \\
\hline Charlson-Quan comorbidity index > $2(\%)$ & 5.8 & 13.0 & 7.5 & 8.9 & 10.6 & 13.3 \\
\hline $\begin{array}{l}\geq 6 \text { months calcium/vitamin D during last } 24 \\
\text { months }(\%)\end{array}$ & 33.2 & 37.8 & 30.1 & 36.1 & 31.1 & 63.0 \\
\hline Treatment with proton pump inhibitors (\%) & 30.8 & 34.3 & 38.3 & 39.9 & 36.7 & 36.8 \\
\hline Pre-packaged drug dispensing (ApoDos) (\%) & 1.2 & 8.3 & 2.9 & 14.0 & 17.3 & 38.8 \\
\hline \multicolumn{7}{|l|}{ Post-index treatment ${ }^{1}(\%)$} \\
\hline Alendronate & 82.9 & 82.3 & 88.7 & 88.0 & 88.6 & 3.2 \\
\hline Risedronate & 12.5 & 6.3 & 7.9 & 6.1 & 5.5 & 0.2 \\
\hline Denosumab & 4.7 & 11.4 & 2.3 & 3.8 & 4.3 & 0.4 \\
\hline Zoledronate & 6.6 & 12.2 & 2.5 & 2.5 & 2.9 & 0.3 \\
\hline Raloxifene & 0.6 & 0.0 & 0.6 & 0.3 & 0.4 & 0.0 \\
\hline Teriparatide & 2.8 & 2.4 & 0.4 & 0.2 & 0.3 & 0.0 \\
\hline Number of hip DXA scans during follow-up (mean) & 2.4 & 2.2 & N/A & N/A & N/A & N/A \\
\hline Baseline total hip BMD (mean $\mathrm{g} / \mathrm{cm} 3(\mathrm{SD}))^{2}$ & $0.56(0.17)$ & $0.50(0.17)$ & $\mathrm{N} / \mathrm{A}$ & $\mathrm{N} / \mathrm{A}$ & $\mathrm{N} / \mathrm{A}$ & $\mathrm{N} / \mathrm{A}$ \\
\hline Baseline total hip T-score (SD) ${ }^{2}$ & $-2.06(0.86)$ & $-2.45(0.92)$ & $\mathrm{N} / \mathrm{A}$ & $\mathrm{N} / \mathrm{A}$ & $\mathrm{N} / \mathrm{A}$ & $\mathrm{N} / \mathrm{A}$ \\
\hline
\end{tabular}

${ }^{1}$ Switching allowed during follow-up

${ }^{2}$ Within 12 months before or after treatment start

$(p<0.05)$ with a baseline TH T-score $\leq-2.5 \mathrm{SD}(+0.6 \%$ units per year) and use of glucocorticoids $(-0.4 \%$ per year). The use of proton pump inhibitors (PPIs) was not significantly associated with percent change per year in TH BMD.

When only including women persistent to treatment during follow-up, the TH BMD increase was higher, with percent increase after 3 years reaching $8.9 \%$ and $7.1 \%$ in women 60-79 and 80+, respectively. This is to be compared with 6.7 and $5.9 \%$ units in the whole population with repeated DXA scans. The adjusted linear percent change in TH BMD was estimated at $+1.95 \%$ units $\left[\mathrm{CI}_{95} 1.79-2.11\right]$ per year, and there was no statistically significant difference between age groups $(p=0.636)$. TH BMD increases of $\sim 20 \%$ units were observed in women persistent to treatment for 6-8 years in both age groups, but these results should be interpreted with caution given the small patient numbers and risk of selection bias.

\section{Analysis 2: fracture incidence in treated patients used as own control (0-3 months vs. 4-15 months)}

Analysis of fracture incidence during 0-3 months after treatment start as a proxy for untreated fracture risk (Table 4) indicated that IRRs for change in fracture risk during treatment were similar across age groups but different across fracture types. There were no statistically significant differences between the age groups. 


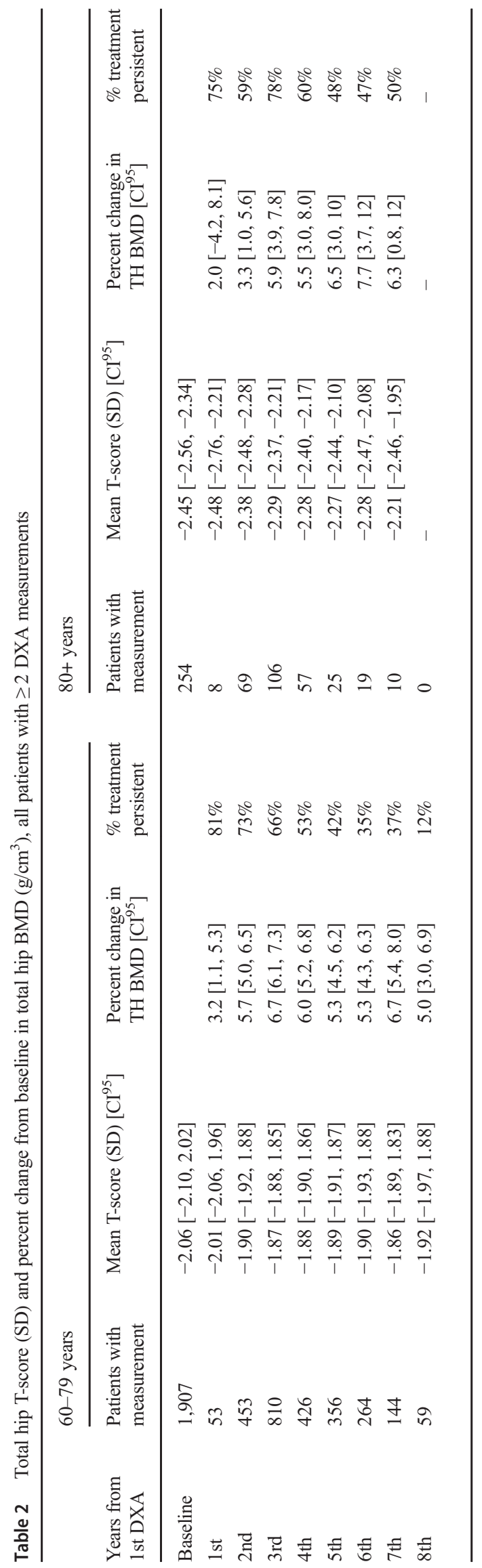

Analysis 3: fracture incidence and mortality associated with osteoporosis treatment vs. calcium/vitamin D after clinical fracture in women $\mathbf{8 0}$ years or older

Comparing the two groups (Fig. 1) showed that patients receiving osteoporosis treatment (ITT group) had lower mortality and lower fracture risk than patients who started calcium/vitamin D. The adjusted Cox model with any fracture as the outcome estimated a HR of 0.77 [0.71-0.83], and the competing risk model estimated a HR of 0.78 [0.72-0.85], indicating that the incorporation of mortality as a competing risk should not change the interpretation. The lower crude mortality (HR 0.51 [0.47-0.55]) in patients receiving osteoporosis treatment indicated that treatment allocation after fracture in the age 80+ strata was not random. Excluding patients with hip fracture as their index fracture did not change this interpretation (HR 0.58).

\section{Discussion}

Pharmaceutical prevention of secondary fractures in the women older than 80 years is rare when compared with younger women, and there are likely several reasons for this. Uncertainty regarding treatment effectiveness, concerns about polypharmacy, frailty and limited life expectancy, views on natural ageing, and reduced patient self-advocacy in the elderly are factors that partly may explain this discrepancy. This study aimed at investigating the real-world effectiveness of osteoporosis treatment in the oldest old women (80+) compared with younger women (60-79 years).

The use of non-randomized retrospective data to estimate effectiveness can never replace randomized trials, because the analysis will always be limited by some degree of bias. However, real-world effectiveness can provide an important complement in that large samples efficiently can be acquired to allow for the study of comparative effectiveness, subgroups, interactions, or rare safety events. Possibly even more important is that studies can be performed for the actual context and population in which the treatments are used in clinical practice. We choose to analyse treatment of the oldest old vs. younger women from several aspects to allow them to complement and validate each other.

\section{Analysis 1: percent change in BMD in treated women 60-79 and 80 years or older}

Percent change in TH BMD was largely the same in both age groups, and the mean percent change in TH BMD over time in treated patients was very similar to what has been reported in an RCT for up to 10 years by Bone and colleagues [21]. Apart from the lack of randomization and a placebo control, the approaches differed in that our analysis was performed on a sample with repeated BMD measurements in patients starting 
Table 3 Total hip T-score (SD) and percent change from baseline in total hip BMD $\left(\mathrm{g} / \mathrm{cm}^{3}\right)$, persistent patients with $\geq 2 \mathrm{DXA}$ measurements

\begin{tabular}{llllll}
\hline Years from 1st DXA & $60-79$ & & $80+$ & \\
\cline { 2 - 3 } \cline { 5 - 6 } \cline { 5 - 6 } & $\begin{array}{l}\text { Patients with } \\
\text { measurement }\end{array}$ & $\begin{array}{l}\text { Percent change in } \\
\text { TH BMD }\left[\mathrm{CI}^{95}\right]\end{array}$ & & Patients with measurement & $\begin{array}{l}\text { Percent change in } \\
\text { TH BMD [CI }\end{array}$ \\
\hline Baseline & 1152 & & 166 & \\
1st & 43 & $3.9[1.8,5.9]$ & 6 & $1.0[-5.1,7.0]$ \\
2nd & 330 & $7.5[6.7,8.3]$ & & 41 & $4.5[1.9,7.0]$ \\
3rd & 531 & $8.9[8.2,9.6]$ & & 83 & $7.1[5.2,9.1]$ \\
4th & 227 & $9.1[8.1,10]$ & & 34 & $8.6[5.8,11.3]$ \\
5th & 148 & $7.9[6.8,9.1]$ & & 12 & $7.2[2.8,11.5]$ \\
6th & 93 & $9.5[8.1,10.9]$ & 9 & $18.8[13.8,23.7]$ \\
7 th & 53 & $9.7[7.9,11.6]$ & 5 & $19.5[12.9,26.2]$ \\
8th & 7 & $21.1[16,26.1]$ & - & - \\
\hline
\end{tabular}

treatment ( $\geq 2$ DXA scans). A natural consequence of this is that follow-up BMD was estimated in different individuals at different time points. There is a risk of bias in that the number and timing of BMD measurements may be associated with the measurement results, but no such clear pattern was observed. It was beyond the scope of this study to analyse BMD development with individual treatments separately, but it may be worthwhile to revisit this in future research.

BMD change in patients fully persistent to treatment during follow-up was generally higher, as expected. Like for the entire BMD population, there was no statistically significant difference of the linear BMD change per year between women 60-79 years and $80+$ years. In agreement with previous studies of persistence to osteoporosis treatments and outcomes
$[22,23]$, these results further reinforce the importance of keeping patients on treatment for as long as it is clinically motivated.

\section{Analysis 2: incidence in treated patients used as own control (0-3 months vs. 4-15 months)}

Using a method originally proposed by Abelson [10], we could show that fracture incidences were higher during the first 3 months after treatment initiation compared with the following 12 months. This pattern was consistent across both age groups and for all three fracture type outcomes analysed. IRRs were similar between age groups with IRRs (all ages combined) of $0.65,0.74,0.34$, and 0.81 for any fracture, hip
Table 4 Incidence during 0 3 months and 4-15 months after treatment start and corresponding IRRs

\begin{tabular}{|c|c|c|c|c|}
\hline Outcome and age group & No. of fractures & $\begin{array}{l}\text { Incidence rate }(\%) \\
0-3 \text { months }\left[\mathrm{CI}^{95}\right]\end{array}$ & $\begin{array}{l}\text { Incidence rate }(\%) \\
4-15 \text { months }\left[C I^{95}\right]\end{array}$ & $\operatorname{IRR}\left[C I^{95}\right]^{*}$ \\
\hline \multicolumn{5}{|l|}{ Any fracture } \\
\hline 60-79 years & 2992 & $6.08[5.74,6.44]$ & $3.83[3.66,4.01]$ & $0.63[0.58,0.68]$ \\
\hline $80+$ years & 2219 & $10.41[9.74,11.13]$ & $7.18[6.81,7.57]$ & $0.69[0.63,0.75]$ \\
\hline All ages & 5211 & $7.39[7.07,7.72]$ & $4.78[4.62,4.95]$ & $0.65[0.61,0.68]$ \\
\hline \multicolumn{5}{|l|}{ Hip fracture } \\
\hline 60-79 years & 474 & $0.90[0.78,1.05]$ & $0.62[0.56,0.70]$ & $0.69[0.57,0.84]$ \\
\hline $80+$ years & 635 & $2.67[2.34,3.05]$ & $2.16[1.96,2.37]$ & $0.81[0.68,0.95]$ \\
\hline All ages & 1109 & $1.43[1.30,1.58]$ & $1.06[0.99,1.14]$ & $0.74[0.65,0.84]$ \\
\hline \multicolumn{5}{|l|}{ Vertebral fracture } \\
\hline 60-79 years & 583 & $1.84[1.66,2.04]$ & $0.48[0.42,0.54]$ & $0.26[0.22,0.31]$ \\
\hline $80+$ years & 431 & $2.92[2.58,3.32]$ & $0.98[0.85,1.14]$ & $0.34[0.28,0.41]$ \\
\hline All ages & 1014 & $2.17[2.00,2.35]$ & $0.62[0.57,0.69]$ & $0.29[0.25,0.33]$ \\
\hline \multicolumn{5}{|l|}{$\mathrm{NHNV}^{* *}$ fracture } \\
\hline $60-79$ years & 1935 & $3.34[3.09,3.61]$ & $2.70[2.56,2.85]$ & $0.81[0.73,0.89]$ \\
\hline $80+$ years & 1153 & $4.82[4.37,5.32]$ & $3.94[3.67,4.24]$ & $0.82[0.72,0.93]$ \\
\hline All ages & 3088 & $3.79[3.56,4.02]$ & $3.06[2.93,3.19]$ & $0.81[0.75,0.87]$ \\
\hline
\end{tabular}

*Incidence rate ratios $<1$ means that incidence was higher during the first 3 months after treatment initiation **Non-hip/non-vertebral 
Fig. 1 Incidence of any fracture (a) and mortality (b) in treatmentnaïve women 80 years or older receiving osteoporosis treatment or calcium/vitamin D after a clinical fracture
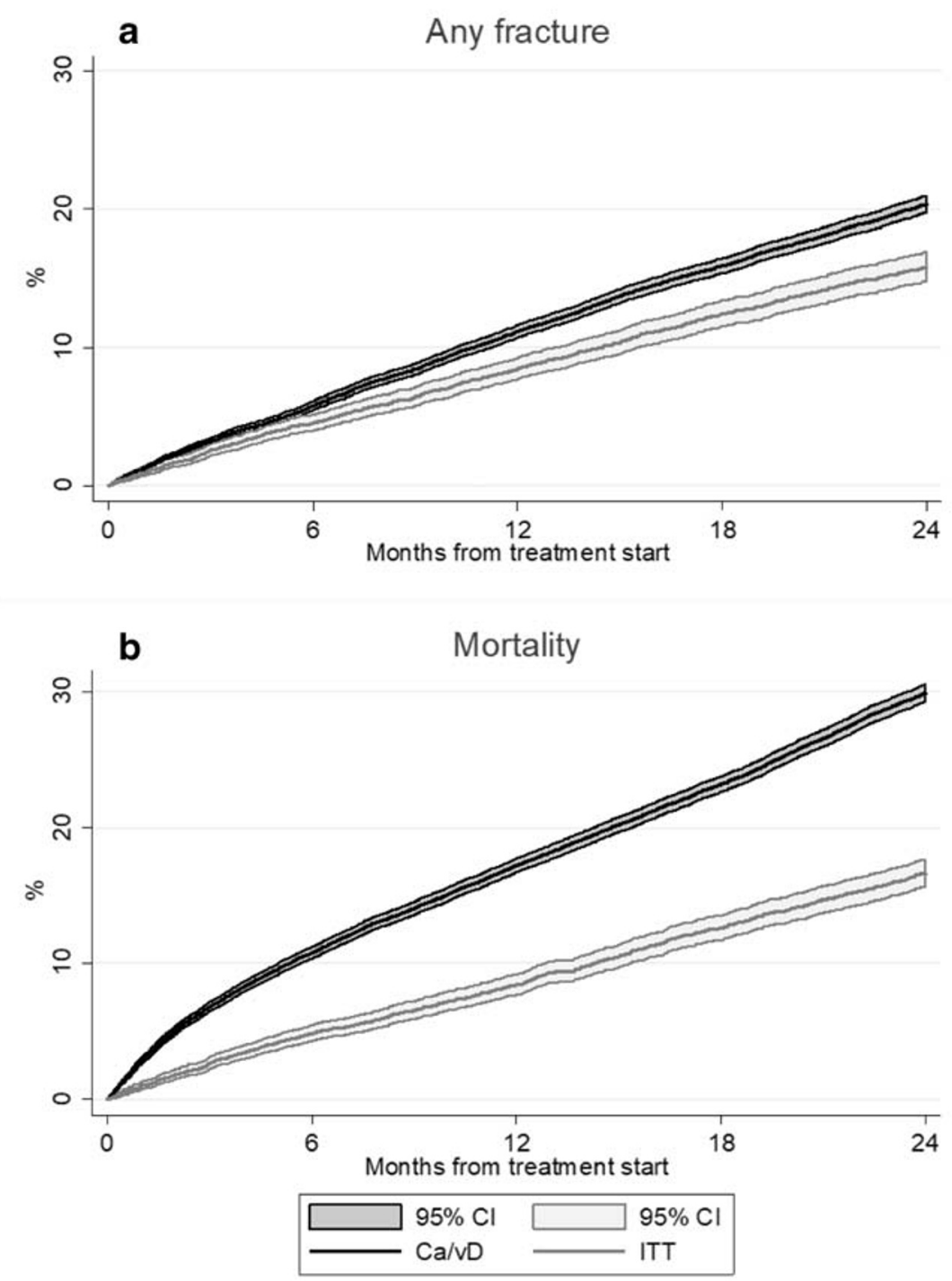

fracture, vertebral fracture, and $N H N V$, respectively. These estimates are comparable with the results reported by Abelson et al. [10] as well as estimates from the RCT metaanalysis of bisphosphonate conducted by NICE, which reported HRs of $0.85,0.45$, and 0.79 for hip fracture, vertebral fracture, and non-vertebral fracture, respectively [24]. However, such comparisons alone cannot validate the method, which rests on the assumption that the first 3 months of treatment are representative of a patient's untreated risk [25] and that treatment is fully effective during the following 12 months. The approach is useful since it allows for the comparison of groups with different characteristics by using patients as their own controls. More typical comparisons when groups or products are compared with each other are often subject to indication bias, where the reasons for an individual's group allocation are associated with the outcome variable. Such bias can be addressed by using propensity scores or multivariate adjustment, but unobserved confounding may make the interpretation of results challenging [26].

\section{Analysis 3: fracture incidence and mortality associated with osteoporosis treatment vs. calcium/vitamin D after clinical fracture in women 80 years or older}

This analysis clearly showed that treatment choice after fracture in the oldest old is not random. This despite that fracture risk assessment with a BMD measurement and/or treatment is rare in this group, and most Swedish patients sustaining a fracture after the age of 80 years will have a fracture risk warranting treatment, irrespective of the presence of other risk factors. For example, the 10 -year probability of a major osteoporotic fracture in a Swedish 80-year-old woman with a previous fracture, normal BMI, and no other risk factors is 
estimated at $39 \%$ by the FRAX algorithm (https://www. sheffield.ac.uk/FRAX). Moreover, our previous research on the impact of risk factors in the oldest old indicated that factors, other than total hip BMD and previous fracture, added limited value to the fracture risk assessment (NB: data on fall risk, smoking and heredity was not available) [14]. Calcium/vitamin D therapy is not recommended for fracture prevention in Swedish patients $<80$ years but has been shown in a meta-analysis to confer moderate risk reductions in patients $>80$ years, with pooled RRs ranging from 0.95 to 0.84 , depending on fracture type [27]. Besides being the standard comparator in placebo-controlled RCTs in osteoporosis, calcium/vitamin D was chosen as a comparator because these patients also have been assessed to need some type of treatment after their fracture. Nonetheless, some patient characteristics and mortality were clearly different when comparing patients receiving alendronate and calcium/vitamin D after fracture. Patients receiving only calcium/vitamin D had more often had a hip fracture and less often a vertebral fracture as the index fracture, had more comorbidities, and were more than twice as likely to receive pre-packaged drug dispensing, which indicates a higher need for assistance, like home care or different types special living accommodations. Mortality was twice as high in patients receiving calcium/vitamin $\mathrm{D}$, which to some extent may be a result of avoided fractures but is still suggesting that treatment decisions in this population may focus more on morbidity than on fracture risk. Omitting hip fracture patients in a sensitivity analysis did not substantially change this interpretation (Mortality HR 0.58), indicating that the differences in mortality only partly can be explained by the observed differences in the distribution of index fracture types. In the adjusted multivariate fracture analysis, osteoporosis medication was associated with a $23 \%$ lower risk of any fracture compared with calcium/vitamin D, but this estimate should be interpreted with caution given the differences in patient profiles. The exact same risk reduction was estimated by Axelsson et al. [11] who studied alendronate vs. no treatment in a similar fashion and population but with untreated matched controls instead of calcium/vitamin D. The more balanced groups achieved by Axelsson and colleagues with matching reduced the mortality difference between the groups (HR 0.88) but instead limited the possibility to study how these populations can be characterized in the clinical setting. Irrespective of whether the approach employed in the present study is useful for measuring effectiveness, it is noteworthy how many patients $>80$ years are treated only with calcium/vitamin D after fracture but who possibly would benefit from osteoporosis treatment ( $\sim 4$ times the osteoporosis treatment group size).

\section{Limitations}

When treatment effectiveness is studied in the real-world setting, it is by design intended that patients should be treated without strict criteria or frequent visits, adherence is not compulsory, and switching between treatments occurs. Apart from this, the analyses are limited by several aspects in the context of drawing inference regarding effectiveness. The absence of randomization will introduce indication bias, where unobserved characteristics that are unevenly distributed between study groups may be associated with the outcome. Furthermore, zoledronate has over time more often been distributed directly via the hospitals instead of pharmacies. Because only drugs dispensed at pharmacies are captured in the Prescribed Drugs Register, it is likely that some patients who appear to have been prescribed only calcium/vitamin D also were prescribed zoledronate during the follow-up period, which should be factored into the interpretation of the association with fracture risk found in analysis 3 .

\section{Conclusions}

Our results indicate that osteoporosis medication works in women older than 80 years and that the magnitude of effect is similar to what we estimated in younger women and to what has been reported in randomized trials. Using patients as their own control appears to be a useful method for eliminating indication bias and measuring treatment effect in osteoporosis. The choice between osteoporosis treatment and calcium/ vitamin $\mathrm{D}$ after fracture in Swedish women $\geq 80$ years is not random but appears associated with the patient's health status and presence of vertebral fractures, rather than the known risk profile of sustaining a fracture at a high age.

Acknowledgements Open access funding provided by Karolinska Institute.

Funding information This study was funded by Amgen.

\section{Compliance with ethical standards}

Conflict of interest OS, RL and GO are employed by Quantify Research, which has received consultancy fees from several pharmaceutical companies marketing osteoporosis drugs. $\mathrm{K} \AA$ has received lecture and consultancy fees from Amgen, UCB, Merck, Sandoz, Renapharma, and Eli Lilly. AS has received lecture fees from Amgen, Mylan and Eli Lilly. JO is employed by Amgen and is an Amgen stock owner. ÖL has no conflict of interest.

Open Access This article is licensed under a Creative Commons Attribution-NonCommercial 4.0 International License, which permits any non-commercial use, sharing, adaptation, distribution and reproduction in any medium or format, as long as you give appropriate credit to the original author(s) and the source, provide a link to the Creative Commons licence, and indicate if changes were made. The images or other third party material in this article are included in the article's Creative Commons licence, unless indicated otherwise in a credit line to the material. If material is not included in the article's Creative Commons licence and your intended use is not permitted by statutory regulation or exceeds the permitted use, you will need to 
obtain permission directly from the copyright holder. To view a copy of this licence, visit http://creativecommons.org/licenses/by-nc/4.0/.

\section{References}

1. Cummings SR, Melton LJ (2002) Epidemiology and outcomes of osteoporotic fractures. Lancet 359:1761-1767

2. Amin S, Achenbach SJ, Atkinson EJ, Khosla S, Melton LJ (2014) Trends in fracture incidence: a population-based study over 20 years. J Bone Miner Res 29:581-589

3. Kanis JA, Johnell O, Oden A, Sembo I, Redlund-Johnell I, Dawson A, De Laet C, Jonsson B (2000) Long-term risk of osteoporotic fracture in Malmo. Osteoporos Int 11:669-674

4. Ström O, Borgström F, Kanis JA, Compston J, Cooper C, McCloskey EV, Jönsson B (2011) Osteoporosis: burden, health care provision and opportunities in the EU. Arch Osteoporos 6: 59-155

5. Leibson CL, Tosteson AN, Gabriel SE, Ransom JE, Melton LJ (2002) Mortality, disability, and nursing home use for persons with and without hip fracture: a population-based study. J Am Geriatr Soc 50:1644-1650

6. Gullberg B, Johnell O, Kanis J (1997) World-wide projections for hip fracture. Osteoporos Int 7:407-413

7. Rosengren BE, Karlsson MK (2014) The annual number of hip fractures in Sweden will double from year 2002 to 2050: projections based on local and nationwide data. Acta Orthop 85:234-237

8. Kannus P, Parkkari J, Sievänen H, Heinonen A, Vuori I, Järvinen M (1996) Epidemiology of hip fractures. Bone 18:S57-S63

9. Rizzoli R, Branco J, Brandi M-L, Boonen S, Bruyère $\mathrm{O}$, Cacoub $\mathrm{P}$, Cooper C, Diez-Perez A, Duder J, Fielding R (2014) Management of osteoporosis of the oldest old. Osteoporos Int 25:2507-2529

10. Abelson A, Ringe J, Gold D, Lange J, Thomas T (2010) Longitudinal change in clinical fracture incidence after initiation of bisphosphonates. Osteoporos Int 21:1021-1029

11. Axelsson KF, Wallander M, Johansson H, Lundh D, Lorentzon M (2017) Hip fracture risk and safety with alendronate treatment in the oldest-old. J Intern Med 282:546-559

12. Hernlund E, Svedbom A, Ivergård $\mathrm{M}$, Compston J, Cooper C, Stenmark J, McCloskey EV, Jönsson B, Kanis JA (2013) Osteoporosis in the European Union: medical management, epidemiology and economic burden. Arch Osteoporos 8:136

13. Spångéus A, Åkesson K, Ljunggren Ö, Banefelt J, Karlsson L, Ortsäter G, Libanati C, Toth E, Ström O (2017) OP0050 the treatment gap after fracture in osteoporosis patients in Sweden. BMJ Publishing Group Ltd

14. Lauppe R, Akesson KE, Ljunggren O, Spangeus A, Ortsater G, Feudjo-Tepie M, Strom O (2019) Differing impact of clinical factors on the risk of fracture in younger and older women in the general population and an osteoporosis clinic population. Arch Osteoporos 14:45
15. Netelenbos C (1999) Bone densitometry in clinical practice; application and interpretation. Eur J Obstet Gynecol Reprod Biol 83: 233-233

16. Feldstein AC, Weycker D, Nichols GA, Oster G, Rosales G, Boardman DL, Perrin N (2009) Effectiveness of bisphosphonate therapy in a community setting. Bone 44:153-159

17. Morin S, Rahme E, Behlouli H, Tenenhouse A, Goltzman D, Pilote L (2007) Effectiveness of antiresorptive agents in the prevention of recurrent hip fractures. Osteoporos Int 18:1625-1632

18. Curtis JR, Westfall AO, Cheng H, Lyles K, Saag KG, Delzell E (2008) Benefit of adherence with bisphosphonates depends on age and fracture type: results from an analysis of 101,038 new bisphosphonate users. J Bone Miner Res 23:1435-1441

19. Landfeldt E, Strom O, Robbins S, Borgstrom F (2012) Adherence to treatment of primary osteoporosis and its association to fractures-the Swedish adherence register analysis (SARA). Osteoporos Int 23:433-443

20. Rabenda V, Mertens R, Fabri V, Vanoverloop J, Sumkay F, Vannecke C, Deswaef A, Verpooten GA, Reginster JY (2008) Adherence to bisphosphonates therapy and hip fracture risk in osteoporotic women. Osteoporos Int 19:811-818

21. Bone HG, Hosking D, Devogelaer JP, Tucci JR, Emkey RD, Tonino RP, Rodriguez-Portales JA, Downs RW, Gupta J, Santora AC, Liberman UA, Alendronate Phase III Osteoporosis Treatment Study Group (2004) Ten years' experience with alendronate for osteoporosis in postmenopausal women. N Engl J Med 350: 1189-1199

22. Meijer WM, Penning-van Beest FJ, Olson M, Herings RM (2008) Relationship between duration of compliant bisphosphonate use and the risk of osteoporotic fractures. Curr Med Res Opin 24: 3217-3222

23. Lindsay R, Watts N, Lange J, Delmas P, Silverman S (2013) Effectiveness of risedronate and alendronate on nonvertebral fractures: an observational study through 2 years of therapy. Osteoporos Int 24:2345-2352

24. Davis S, Martyn-St James M, Sanderson J, et al. (2015) Bisphosphonates for preventing osteoporotic fragility fractures (including a partial update of NICE technology appraisal guidance 160 and 161). Technology Assessment Report: Final report to the National Institute for Health and Care Excellence

25. Inderjeeth CA, Chan K, Kwan K, Lai M (2012) Time to onset of efficacy in fracture reduction with current anti-osteoporosis treatments. J Bone Miner Metab 30:493-503

26. Karlsson L, Mesterton J, Tepie MF, Intorcia M, Overbeek J, Strom O (2017) Exploring methods for comparing the real-world effectiveness of treatments for osteoporosis: adjusted direct comparisons versus using patients as their own control. Arch Osteoporos 12:81

27. Avenell A, Mak JC, O'Connell D (2014) Vitamin D and vitamin D analogues for preventing fractures in post-menopausal women and older men. Cochrane Database Syst Rev:CD000227

Publisher's note Springer Nature remains neutral with regard to jurisdictional claims in published maps and institutional affiliations. 